\title{
The Effect of Ejectors on Reduction of Indoor Air Pollution in the Welding Room
}

\author{
Sattar Yunus*†, Makmur Saini**, Rizal Sultan***, Rusdi Nur**** and Ibrahim***** \\ *Department of Mechanical Engineering, Universitas Muslim Indonesia, Makassar, 90231, Indonesia \\ **Department of Energy Conversion, Ujung Pandang State Polytechnic, Makassar, 90245, Indonesia \\ ***Department of Electrical, Ujung Pandang State Polytechnic, Makassar, 90245, Indonesia \\ ****Department of Mechanical Engineering, Ujung Pandang State Polytechnic, Makassar, 90245, Indonesia \\ *****Department of Mechanical Engineering, Polytechnic of Industry, Makassar, 90213, Indonesia \\ †Corresponding author: Sattar Yunus; sattar.teknik@umi.ac.id
}

Nat. Env. \& Poll. Tech.

Website: www.neptjournal.com

Received: 22-11-2019

Revised: 15-12-2019

Accepted: 01-03-2020

\section{Key Words:}

Indoor air pollution

Ejectors

Carbon monoxide

Nitrogen monoxide

Total suspended particles

\begin{abstract}
In this study, the ejector installation has been designed and processed according to the plan and further investigated the effect of the ejector's performance on reducing air pollutants in a welding chamber. This is done after gas and dust particles appear during the welding process. The measurement of air pollutants was carried out in two conditions. The first condition during the welding process was without using the ejector and the second condition is when the welding process continues and the ejector runs simultaneously. The measurements were made for carbon monoxide (CO) gas, nitrogen monoxide (NO) gas and total suspended particles. The ambient gas sampler was used in measuring $\mathrm{CO}$ and NO gases, while the Staflex air sampler measures dust particles. The results show that when the ejector is run or in the second condition, carbon monoxide and nitrogen monoxide and total dust particles are lower in concentration compared to the situation when the ejector is not running.
\end{abstract}

\section{INTRODUCTION}

The rapid industrialization over the past two decades has caused many problems in the environment, including air pollution whose influence has started to be felt and even become a pivotal problem today and certainly requires special attention in the development of a country (Lima et al. 2009), including in the City of Makassar, South Sulawesi Province. It is one of the cities in Indonesia which has air pollution trends increasing from year to year (Sattar et al. 2012, Sattar et al. 2019). The increasing number of the population is not only happening in developed countries but also in developing countries that have caused widespread air pollution (WHO 2005). Urban air pollution affects the health, well-being and lives of hundreds of millions of people, women and children every day in Asia. It was reported that outdoor air pollution causes around 537,000 deaths annually, indoor air pollution causes more than double the number of deaths (WHO 2002); this means that indoor pollution causes a greater impact than outdoor pollution especially in indoor activities that directly produce gases and particles (dust) which are quite dangerous for those exposed.

Based on the discoveries of historical objects, it can be seen that the technique of connecting metal known today with welding has been known since prehistoric times, for example, the contrasting of copper-gold alloy metal and lead-tin disordering. According to the information, it has been known and practised in the span of 4000 to 3000 years $\mathrm{BC}$ and alleged sources of heat come from burning wood and charcoal. In the $19^{\text {th }}$ century, welding technology developed rapidly due to the use of electrical energy (Suharno 2008). According to Deutsche Industrie Normen (DIN), welding is a metallurgical bond on alloy metal joints that is carried out in hot and liquid conditions, further explained that welding is a process where the same material and type are combined together so that a connection is formed through the chemical bonds produced from the use of heat and pressure (Suharno 2008). Since there is a heat source, it will produce gases and particles where the gases that arise are dust (particles) in large welding fumes ranging from $0.2 \mu \mathrm{m}$ to $3 \mu \mathrm{m}$. The chemical composition of welding smoke dust depends on the type of welding and electrodes used. When the hydrogen type electrode is low, there will be fluorine $(\mathrm{F})$ and potassium oxide $\left(\mathrm{K}_{2} \mathrm{O}\right)$ in smoke dust. In electric arc welding without gas, the smoke will contain a lot of magnesium oxide $(\mathrm{MgO})$. The gases that occur during welding are carbon monoxide ( $\mathrm{CO}$ ), carbon dioxide $\left(\mathrm{CO}_{2}\right)$, ozone $\left(\mathrm{CO}_{3}\right)$ and nitrogen monoxide gas (Wiryosumarto \& Okumura 2004). In line with that when the welding process takes place, there are dangerous gases which need to be considered such as carbon monoxide gas 
(CO). This gas has a high affinity for haemoglobin ( $\mathrm{Hb})$ which will reduce the absorption of oxygen, and the condition of the total suspended particles (TSP) also needs attention in the welding room (Harsono 1996).

In the effort to minimize the gases and harmful particles that arise in the room when welding takes place, a system or tool is required that can reduce gases or particles that occur. One method that can be done is by using the ejector method. The projector has succeeded used for polluted gas cleaning applications over the past few decades because of their ability to handle gases containing pollutants such as vapour, gas and solid/liquid aerosols up to $0.1 \mu \mathrm{m}$ (Dutton et al. 1982, Subramarian et al. 2006). In line with this, it was stated that the ejector is one of the most important devices used in the industry. This device has two main tasks. One is to make a vacuum and remove gas and the other is to mix it in liquid. One of the tasks above or both can be considered in designing and using an ejector (Stefan \& Hamjak 2008, Gamisansa 2002). In general, the main function of the ejector is to achieve maximum secondary flow in each of the main operating conditions given and to compress entangled masses in the ejector to the necessary release conditions (Chou 1996).

Based on this description, we will investigate in this study whether there is a reduction in the concentration of gases and particles in the air that arise specifically carbon monoxide (CO), nitrogen monoxide (NO) and total suspended particles (TSP) with tools that have been designed with the ejector method.

\section{MATERIALS AND METHODS}

\section{Ejector Installation}

The design of the ejector installation consisting of several core components such as cylindrical joints, reservoirs and other components has been done and completed the installation as shown in Fig. 1.

\section{Tools and Procedure Sampling}

The implementation of the study is to examine the extent of the influence of the ejector tool that has been designed and made but will require direct testing to the actual environment, namely the industrial environment. As a testing phase, this tool is carried out in the student's welding practice room at the Makassar Industrial Engineering Polytechnic (ATI) Makassar, with the consideration that in the welding room when welding takes place there will be a range of air conditions with bad air condition, which certainly has an impact on welders or students who temporarily practice welding.

The entire air sampling process uses tools from the Environmental Engineering Centre and Makassar Class I Disease Control whose equipment is available and sufficient for sampling and also for the analysis of air samples that have been taken. The tool used for sampling air for gas is Ambient Gas Sampler (Impinger Model: MD-51MP), while TSP samples are used by the Staflex Air Sampler tool. Sampling was carried out in two air test conditions, namely:

1. Condition I (Ejector OFF): Retrieval and analysis of air samples when welding practices are taking place but the ejector has not operated. The data generated are as a control to see how much influence the ejector has.

2. Condition II (Ejector ON): Retrieval and analysis of air samples while ongoing welding practices and temporarily operated ejectors. Data generated will be compared with the data generated in the condition I.

\section{Sampling Implementation Procedures}

Supply installation equipment systems with electric power, throat length used was $30 \mathrm{~cm}$ (Saini et al. 2018). The pump

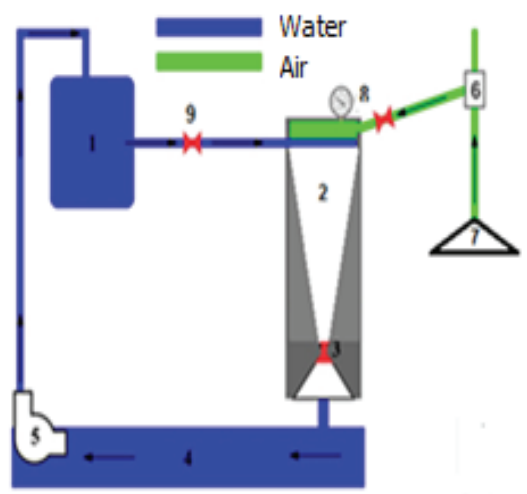

Note:

1. Cylinder tube 1

2. Cylinder tube 2

3. Valve

4. Water reservoir

5. Pump

6. Connecting Tube

7. Suction Funnel

8. Vacuum gauge

9. Valve

Fig. 1: Ejector installation design results. 
engine (5) was operated to fill the reservoir (4). The valve (9) and valve (10) were opened and the valve (3) was closed until the cylinder (2) can be fully charged. The valve 9 and valve 10 were closed after the cylinder 2 was filled. The initial height of the reservoir water level (4) was measured and the ejector was run by the opening valve (3) and valve (10) so that the water is circulated continuously. The vacuum value was measured in the vacuum gauge (8) after opening the valve (10). Notes were taken and the level of water in the reservoir (4) was maintained. The throat ejector (3), which is $30 \mathrm{~cm}$ long, was set and used based on the results of previous tests. The ambient gas sampler tools and Staflex air samplers were operated and the time to start operating the tool in this step was recorded. Sampling tools were operated for 60 minutes, with three sampling times at 9-10, 10-11, 13-14 (in the case of students while doing welding, such as conditions when taking samples without running an ejector). After enough time, the ejector and the sampler were stopped. Air samples were taken to the BTKL-PP Laboratory for analysis.

\section{RESULTS AND DISCUSSION}

The air measurements in the welding room for carbon mon- oxide are shown in Fig. 2. With the ejector condition not yet executed (OFF) the sampling at 9-10 a.m. showed CO concentrations of 2,384 ppm, at 11-12 a.m. of $2.43 \mathrm{ppm}$, and at 1-2 p.m. of 2,425 ppm. When the ejector is ON, at 09-10 a.m. CO concentration was $2,378 \mathrm{ppm}$, at $11-12$ was 2.41 ppm, and at 1-2 p.m. was 2.39 ppm. Concentration when the ejector is carried out at all hours, the nine samples show a decrease in concentration, which more noticeably decreased at 1-2 p.m. This means that the longer the ejector is executed, the more carbon monoxide in the indoor air will be.

Based on the results of the air test for the nitrogen monoxide is shown in Fig. 3. With OFF ejector conditions at sampling at 9-10 a.m., NO concentration was $0.003 \mathrm{ppm}$, at 11-12 a.m. it was $0.004 \mathrm{ppm}$, while at 1-2 p.m. the concentration was $0.0045 \mathrm{ppm}$. Meanwhile, on the ejector ON condition at 9-10 a.m., NO concentration was $0.0025 \mathrm{ppm}$, at $11-12$ a.m. it was $0.0039 \mathrm{ppm}$, while at $1-2$ p.m. it was $0.0044 \mathrm{ppm}$. There appears to be a decrease in NO concentration when the ejector is run, but it is different from carbon monoxide which decreases a bit.

Based on the air measurement results in the welding room for the total suspended particles as shown in Fig. 4,

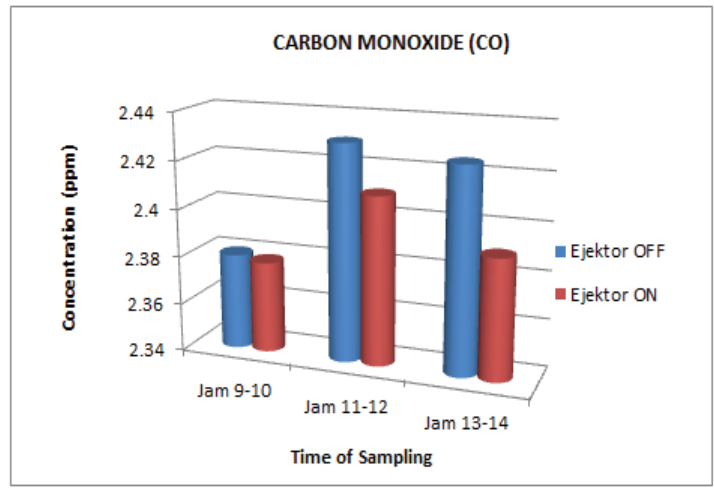

Fig. 2: Graph of $\mathrm{CO}$ concentration in the air when the ejector is OFF and $\mathrm{ON}$.

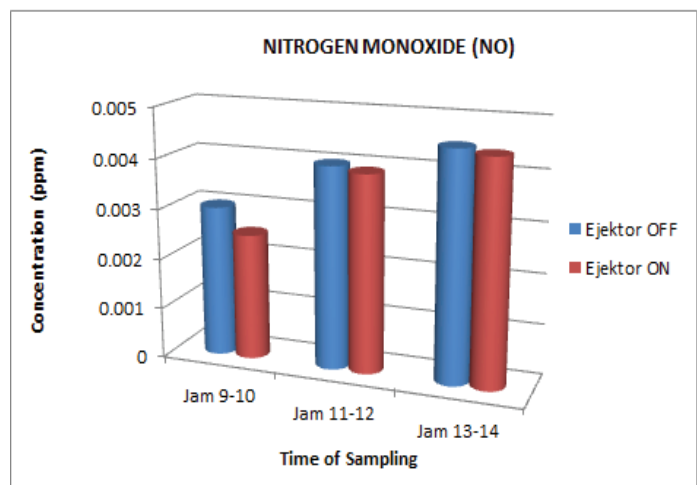

Fig. 3: Graph of the NO concentration in the air when the ejector is OFF and ON 


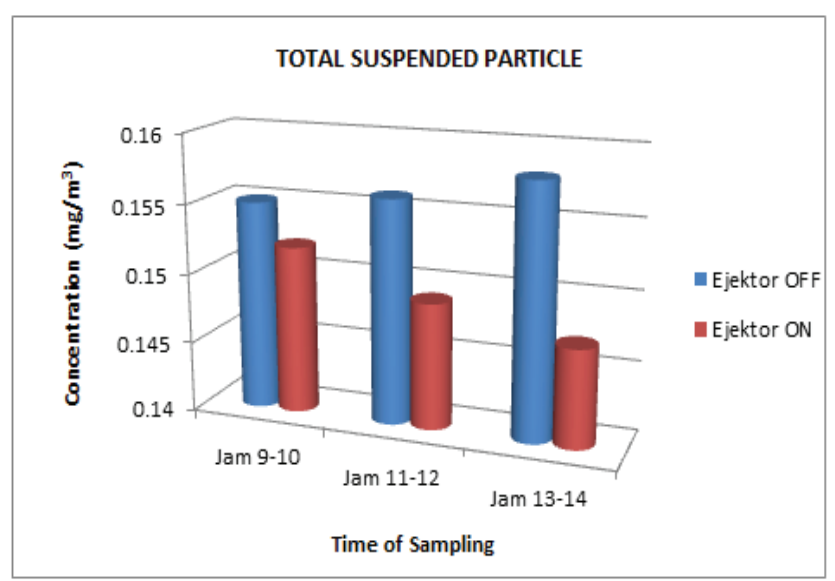

Fig. 4: Graph of TSP concentration in the air when the ejector is OFF and ON.

with the ejector not running, at 9-10 a.m. TSP concentration of $0.155 \mathrm{mg} / \mathrm{m}^{3}$ was obtained, $11-12$ a.m. it was $0.156 \mathrm{mg} /$ $\mathrm{m}^{3}$, while at 1-2 p.m. the concentration was $0.158 \mathrm{mg} / \mathrm{m}^{3}$. While the results of TSP measurements on the condition of the ejector ON at 9-10 a.m., the TSP concentration was $0.152 \mathrm{mg} / \mathrm{m}^{3}$, at $11-12$ a.m. it was $0.149 \mathrm{mg} / \mathrm{m}^{3}$, while at $1-2$ p.m. the concentration was $0.147 \mathrm{mg} / \mathrm{m}^{3}$. There appears to be a decrease in TSP concentration when the ejector was run, also like carbon monoxide, a reduction was seen at 1-2 p.m. sampling.

Based on the graphs of the data shown in Fig. 2 and Fig. 4, it seems that there are differences that can be observed, namely in the carbon monoxide, where the highest concentration in the sampling hours is at 11-12 a.m. both when the ejector is not executed and when the ejector is executed. Whereas in TSP measurements it appears that when the ejector has not been executed, the trend of TSP concentration appears to increase, and when the ejector is carried out, the total dust concentration (TSP) trend is decreasing. From both $\mathrm{CO}$ and TSP measurements, it appears that the total dust concentration decreases more (suspended particles) due to the effect of the ejector $(4.47 \%$ ), compared to carbon monoxide (CO) $(0.78 \%)$. One reason is that the particles have heavier mass than CO. In addition to larger sizes, the particles themselves can be categorized by diameter. If the diameter is smaller or equal to 2.5 microns, it is categorized as fine particles, if the diameter is between 2.5-10 microns it is categorized as coarse particles, whereas when the diameter is greater than 10 microns it is called total dust or total suspended particles (Sattar et al. 2014). The finer the particles have a higher impact on respiratory health (Rashid et al. 2014).

\section{CONCLUSIONS}

In this study, the reduction and recovery of pollutant gases and total dust have been carried out by sucking from the air by vacuum into a tube. Then the pollutant gases and particles are being sent into water that continues to circulate. The conclusions in this study are: There is a reduction in the concentration of carbon monoxide gas and total suspended particles by the operation of the ejector. The longer the ejector is operated, more the carbon monoxide and total suspended particles will be reduced. Compared to carbon monoxide gas, the concentration of total suspended particles appears to have a greater degree of reduction in all hours of sampling. The greater the vacuum, the higher will be the ability to reduce the concentration of carbon monoxide gas and total suspended particles.

\section{ACKNOWLEDGEMENT}

This research was carried out with funding support from the Directorate of Research and Community Service (DRPM) of the Ministry of Research, Technology and Higher Education through the Ujung Padang Polytechnic Unit of Research and Community Service (UPPM), therefore, we extend our full appreciation and gratitude to them.

\section{REFERENCES}

Chou, S. K. 1986. Experimental studies on an air-air jet exhaust pump. ASHRAE Transactions. 4: 497-506.

Dutton, J. C., Mikkelsen, C.D. and Addy, A. L. 1982. A theoretical and experimental investigation of the constant area, supersonic-supersonic ejector. AIAA Journal, 20: 1392-1400.

Gamisansa, X., Sarrab, M. and Lafuente, F. J. 2002. Gas pollutants removal in a single and two-stage ejector venturi scrubber. Journal of Hazardous Materials, B90: 251-266.

Harsono, 1996. Technology of Welding Metal. Pradya Paramita Press, Jakarta.

Lima, E.A.P., Guimaraes, E.C., Pozza, S.A., Barrozo, M.A.S. and Coury, J.R. 2009. A Study of atmospheric particulate matter in a city of the central region of Brazil using time-series analysis. Int. J. Environment Engineering, 1: 1-9.

Rashid, M., Yunus, S., Mat, R., Baharun, S. and Lestari, P. 2014. $\mathrm{PM}_{10}$ 
black carbon and ionic species concentration of urban atmospheric in Makassar of South Sulawesi Province, Indonesia. Atmospheric Pollution Research, 5: 610-615. doi: 10.5094/APR.2014.070.

Saini, M., Nur, R., Yunus, S. and Ibrahim, 2018. The influence of throat length and vacuum pressure on air pollutant filtration using ejector. AIP Conference Proceedings. doi.org/10.1063/1.5042939.

Sattar, Y., Rashid, M., Ramli, M. and Sabariah, B. 2014. Black carbon and elemental concentration of ambient particulate matter in Makassar Indonesia. IOP Conf. Series: Earth and Environmental Science, 18: 012099, doi: 10.1088/1755-1315/18/1/012099.

Sattar, Y., Rashid, M., Mat, R., Baharun, S. and Man, H.C. 2019. Characteristics of the $\mathrm{PM}_{10}$ in the urban environment of Makassar, Indonesia. Journal of Urban and Environmental Engineering, 13(1): 198-2017: doi: 10.4090/juee. 2009. v13n1.198207.

Sattar, Y., Rashid, M., Mat. R. and Puji, L. 2012. A preliminary survey of air quality in Makassar City South Sulawesi Indonesia. Jurnal
Teknologi (Sciences \& Engineering), 57:123-136.

Stefan, E. and Harnjak, P. 2008. Ejector refrigeration: An overview of historical and present developments with emphasis on air-conditioning applications. International Refrigeration and Air Conditioning Conference, U.S.A., 1-8.

Subramarian, G., Natrajan, S.K., Adhimolane, K. and Natarajan, A.T. 2006. Comparison of numerical and experimental investigation of jet ejectors with blower. International Journal of Thermal Science, 84: 134-142.

Suharno, 2008. Principles of Welding Metal and Mettalurgy. UNS Press. Surakarta, Indonesia.

WHO 2002. The World Health Report 2002: Reducing Risks, Promoting Health Life. WHO, Geneva.

WHO 2005. Indoor Air Pollution and Health, Bonn.

Wiryosumarto, H. and Okumura, T. 2004. Technology of Welding Metal. Pradaya Paramita Press, Jakarta. 